
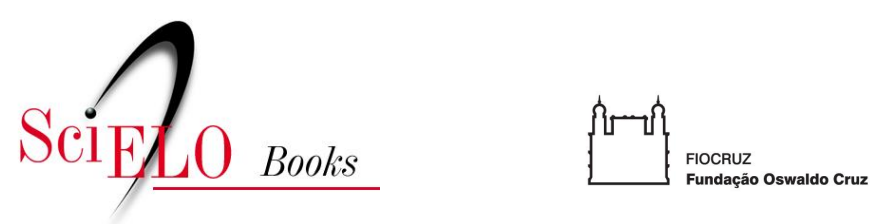

ipea

Aconomica Aplicada

\title{
Sistemas de alocação de recursos a prestadores de serviços a saúde
}

\author{
Maria Alicia Domínguez Ugá \\ Sheyla Maria Lemos Lima
}

\section{SciELO Books / SciELO Livros / SciELO Libros}

UGÁ, MAD., and LIMA, SML. Sistemas de alocação de recursos a prestadores de serviços a saúde. FUNDAÇÃO OSWALDO CRUZ. A saúde no Brasil em 2030 - prospecção estratégica do sistema de saúde brasileiro: estrutura do financiamento e do gasto setorial [online]. Rio de Janeiro:

Fiocruz/Ipea/Ministério da Saúde/Secretaria de Assuntos Estratégicos da Presidência da República, 2013. Vol. 4. pp. 135-168. ISBN 978-85-8110-018-0. Available from SciELO Books <http://books.scielo.org>.

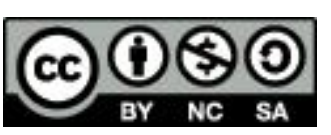

All the contents of this chapter, except where otherwise noted, is licensed under a Creative Commons Attribution-Non Commercial-ShareAlike 3.0 Unported.

Todo o conteúdo deste capítulo, exceto quando houver ressalva, é publicado sob a licença Creative Commons Atribuição Uso Não Comercial - Partilha nos Mesmos Termos 3.0 Não adaptada.

Todo el contenido de este capítulo, excepto donde se indique lo contrario, está bajo licencia de la licencia Creative Commons Reconocimento-NoComercial-CompartirIgual 3.0 Unported. 
Sistemas de Alocação de Recursos a Prestadores de Serviços a Saúde 


\title{
SISTEMAS DE ALOCAÇÃO DE RECURSOS A PRESTADORES DE SERVIÇOS DE SAÚDE
}

\author{
Maria Alicia Domínguez Ugá \\ Sheyla Maria Lemos Lima
}

\section{1 | INTRODUÇÃO}

Já nos anos setenta apontavam Wennberg e Gittelsohn (1973) que "o volume e custos dos tratamentos hospitalares em uma dada comunidade têm mais relação com o número de médicos que lá atuam, suas especialidades médicas e os procedimentos que eles preferem do que com a saúde da população"1. Embora eles estivessem, naquele momento, referindo-se à realidade estadunidense, provavelmente em qualquer sociedade capitalista, ainda hoje, essa afirmação poderia ser reiterada.

Nesse contexto e, particularmente, no âmbito das reformas dos sistemas de saúde dos anos noventa, movidas fundamentalmente por critérios de ajuste macroeconômico (UGÁ, 1997), os sistemas de alocação de recursos (ou "modos de pagamento", como denominado na literatura internacional) a hospitais e prestadores de serviços ambulatoriais passam a ser vistos como um instrumento de contenção da expansão exponencial dos gastos em saúde, tanto pelos sistemas públicos como por sistemas privados que gerem redes de serviços, no modelo de atenção gerenciada (managed care).

Para além dessa questão, a necessária capacidade de condução do sistema de saúde a partir de redes integradas de serviços requer instrumentos de regulação dos prestadores de serviços de saúde, tais como modelos de contratualização entre o gestor público e prestadores e, também, novos sistemas de remuneração aos prestadores de serviços que superem o mero pagamento por serviços previamente prestados.

Ainda, está cada vez mais presente nos debates sobre a gestão de sistemas de saúde a necessidade de qualificar o gasto em saúde, mediante o uso da avaliação econômica para a incorporação de tecnologias: antes de incorporar novas tecnologias médicas é necessário conhecer a relação entre o seu custo adicional em relação às

1 Tradução livre 
tecnologias que lhe antecedem e a efetividade adicional que elas trazem. Segundo o BMJ Clinical Evidence Handbook (BMJ, 2007 apud MAYNARD, 2008), a efetividade de mais da metade da produção de procedimentos médico assistenciais carece de comprovação. Ainda, como afirma Maynard (2008), a incerteza que prevalece em relação à efetividade de grande parte dos procedimentos introduz uma importante variação na prática clínica, de forma que, nas palavras desse autor, "na maior parte dos sistemas de saúde há evidência de que intervenções provadamente custo-efetivas não são realizadas nos pacientes e, o que é mais grave, intervenções inadequadas são feitas nos pacientes sem nenhum benefício e com possível dano"2. Nesse contexto e no sentido de dotar de maior racionalidade técnica a prática médico-assistencial, as formas de contratualização e de alocação de recursos a prestadores hospitalares e ambulatoriais também têm um papel a cumprir, de forma a induzi-los a adotar práticas e tecnologias mais custoefetivas e seguras para os pacientes.

\section{AS FORMAS TRADICIONAIS DE ALOCAÇÃO DE RECURSOS AOS PRESTADORES DE SERVIÇOS}

Esta temática é abordada na literatura internacional sob a denominação de "modos de pagamento" ou "formas de remuneração de serviços médico-assistenciais". Entretanto, como se tentará demonstrar a seguir, nem todas as formas correspondem a um pagamento ou remuneração por serviços previamente prestados. Desse modo, optamos aqui por denominá-las de formas de alocação de recursos a prestadores de serviços médico-assistenciais, hospitalares e/ou ambulatoriais.

Como apresentado em Ugá (1994), os métodos de alocação de recursos a prestadores de serviços hospitalares ou ambulatoriais podem ser classificados a partir do momento em que se dão essas transferências financeiras: se antes da efetiva produção de serviços (alocação ex-ante) ou se depois e em função do volume e tipo da produção apresentada por cada prestador (alocação ex-post).

No primeiro grupo (alocação ex-ante), encontram-se o orçamento global e a alocação de recursos por capitação (ou per capita); no segundo (alocação ex-post), estão os sistemas que se constituem, estes sim, na remuneração por serviços previamente prestados, como é o caso do pagamento por ato médico, do pagamento por diária hospitalar e do pagamento prospectivo por procedimento. Esses cinco métodos são apresentados sucintamente a seguir.

2 Tradução livre 


\section{1 | Sistemas de Alocação de Recursos Ex-Ante}

\subsubsection{A alocação de recursos por orçamento global}

O sistema de alocação de recursos por orçamento global consiste em repasses periódicos de um montante anual de recursos definido através de programação orçamentária elaborada pela unidade de saúde para o período correspondente e negociada com o órgão financiador.

Trata-se de um sistema no qual, embora o montante de recursos esteja formalmente calculado em base à produção prevista para o período em questão (geralmente um ano), as transferências de recursos não estão vinculadas à efetiva produção de serviços. Assim, se por um lado ele possibilita ao órgão financiador uma previsão dos seus gastos e à unidade de saúde uma previsibilidade de suas receitas (desde que não haja o contingenciamento dos recursos e, portanto, atraso na liberação dos mesmos, como tem ocorrido no Brasil com frequência, principalmente a partir de meados dos anos noventa, anos do ajuste macroeconômico), este método de alocação de recursos não traz em si - e em sua forma clássica- nenhum incentivo ao bom desempenho do prestador de serviços, nem em termos quantitativos, nem qualitativos.

\subsection{2 | A alocação de recursos por capitação}

Esta forma de alocação pressupõe a existência de um sistema de saúde regionalizado e hierarquizado, no qual a cada unidade prestadora de serviços esteja vinculada uma população adscrita, previamente definida. Assim, a cada prestador corresponde um montante de recursos (periódico - geralmente anual) que equivale ao número de indivíduos a ele adscritos multiplicado por um valor per capita. Este valor unitário é frequentemente ajustado por risco, tomando-se em conta, pelo menos, o sexo e a idade da população adscrita.

O sistema em questão é utilizado há décadas para a alocação de recursos aos médicos generalistas (general practitioners - GPs) que atuam como porta de entrada no Sistema Nacional de Saúde Inglês e foi, na reforma dos anos noventa, estendido para os gestores do sistema em nível microrregional, isto é, os GP-funholders (gestores de recursos públicos) e as autoridades sanitárias locais.

Na ausência de um sistema de avaliação e controle sistemático, este método de alocação de recursos pode levar à subprodução de serviços, tendo em vista que o valor recebido pelo prestador independe da produção, sendo atrelado ao número de pessoas adscritas - e não ao número de pacientes tratados. Nesse sentido, nas reformas dos noventa introduziu-se no Reino Unido a concorrência dos GPs por clientela, desvinculando-se a adscrição ao local de moradia da população. Entretanto, 
da mesma forma que o orçamento global, apresenta a virtude da previsibilidade do gasto do órgão financiador e da receita do prestador.

\subsection{Sistemas de Alocação de recursos Ex-Post}

Estes constituem modalidades de pagamento por serviços previamente prestados. O valor a ser pago pode ser calculado a priori (prospectivamente) ou a posteriori, como é o caso do pagamento itemizado e do pagamento por diária hospitalar, apresentados a seguir.

\subsubsection{O pagamento por ato médico (ou itemizado)}

Este método vincula o pagamento a serviços previamente efetuados mais especificamente, ao tratamento de cada paciente - e consiste na remuneração discriminada de cada item que compõe o procedimento efetuado (materiais e medicamentos, honorários profissionais, diárias hospitalares e serviços intermediários, tais como exames, dentre outros).

Assim, o valor mensal correspondente a cada prestador equivale ao somatório dos serviços intermediários e finais prestados a cada paciente, multiplicados por seus respectivos valores. Por sua vez, estes últimos são, em alguns casos, negociados previamente entre o órgão financiador e os prestadores e, em outros - menos frequentes, definidos a posteriori a partir dos custos observados (aos quais se adiciona, no caso do setor privado, sua margem de lucro).

Como apontado em Ugá (op.cit.), é evidente que este sistema estimula a sobreutilização de serviços intermediários, principalmente os que proporcionam markups mais elevados e, portanto afeta negativamente a qualidade da atenção médico-assistencial, seja porque pode gerar episódios iatrogênicos, seja por submeter o paciente a desconfortos evitáveis e indesejáveis. Além disso - e em função desse fenômeno- tende a gerar um aumento desnecessário no custo da assistência médica.

\subsubsection{O pagamento por diária hospitalar}

Trata-se evidentemente de um método que remunera exclusivamente as internações hospitalares, não aplicável aos serviços ambulatoriais. Através dele, o valor correspondente periodicamente a cada hospital equivale ao número de diárias (ou seja, ao somatório do tempo de permanência dos pacientes internados no período em questão) multiplicado por um valor unitário atribuído a cada diária. 
O valor da diária é definido a partir do seu custo médico, incluindo ou não os honorários médicos. Em grande parte dos países que adotam este sistema de pagamento, tendo em vista as enormes disparidades de custo de cada tipo de internação (que não só depende do tempo de permanência, mas também dos insumos utilizados, tais como exames complementares e medicamentos usados no período da internação), são definidos valores diferenciados segundo a complexidade do hospital e a clínica (médica, cirúrgica, UTI, etc.).

Vale observar, entretanto, que através deste mecanismo de remuneração os hospitais não são remunerados pelo custo efetivo de cada paciente tratado, o qual pode levar à segregação de alguns pacientes, segundo seja seu quadro nosológico.

Por outro lado, tendo em vista que o hospital recebe por diárias, este método induz ao prolongamento desnecessário do tempo de permanência, tendo em vista que o custo da internação de cada paciente tende a ser decrescente com o tempo, pois a maior parte dos exames complementares de diagnóstico e o ato cirúrgico são geralmente efetuados no início da internação. Em função disso, em alguns países são estipulados valores da diária que decrescem com o tempo de permanência.

De todas as formas, é um método de pagamento altamente insatisfatório pelos motivos a cima apontados e, atualmente, na maior parte dos países que o adotavam na sua forma pura (França e Alemanha, dentre outros), esta forma de remuneração foi associada a outras, constituindo sistemas mistos, discutido em outra seção deste livro.

\subsubsection{O sistema de pagamento prospectivo por procedimento}

Através deste sistema, o prestador de serviços de saúde é remunerado por episódio de tratamento - no caso do hospital, por internação - com valores diferenciados segundo o diagnóstico do paciente. Trata-se de um método prospectivo (e não retrospectivo), porque os valores atribuídos a cada internação são definidos previamente, embora variem segundo o diagnóstico. Assim, o sistema estabelece, na realidade, uma série de preços pré-fixados das internações, por tipo (isto é, o diagnóstico) do paciente. Estes preços independem, portanto, do custo efetivo de cada paciente tratado no episódio de sua internação.

Vale notar que, para ser administrável, tendo em vista a infinidade de diagnósticos (diagnóstico principal e secundário, comorbidades) e de características do paciente (idade), este método de pagamento requer indispensavelmente um sistema de classificação dos pacientes, em grupos homogêneos - fundamentalmente do ponto de vista do custo. Nesse sentido, o primeiro país que adotou o sistema de pagamento prospectivo por procedimento ${ }^{3}$, isto é, os EUA, o fez depois de contar com um sistema de classificação dos pacientes bastante robusto, que estabeleceu os Diagnostic Related

3 ProspectivePayment System (PPS). Ver a esse respeito: https://www.cms.gov/HomeHealthPPS/ 
Groups - DRGs (Grupos Relacionados ao Diagnóstico)4. Este sistema de classificação tem por objetivo subsidiar não só a gestão econômica (interessada no custo das internações), mas também a gestão clínica (interessada no perfil clínico dos casos tratados) e, nesse sentido, constituiu grupos que se pretenderam homogêneos do ponto de vista do custo, definidos da seguinte forma (UGÁ, op.cit.):

- em primeiro lugar, as altas hospitalares são classificadas a partir do diagnóstico principal em grupos de Principais Categorias Diagnósticas (baseados no sistema orgânico afetado e/ou na especialidade médica responsável pelo tratamento);

- a seguir, as altas relativas a tratamentos clínicos (não cirúrgicos) são subdivididas em categorias baseadas no seu diagnóstico principal, enquanto os casos cirúrgicos são agrupados segundo os procedimentos efetuados;

- em um terceiro momento, esses grupos são reagrupados segundo a intensidade de utilização de recursos e, portanto, o seu custo;

- finalmente, a classificação definitiva das altas hospitalares se dá através da constituição de subgrupos clínicos ou cirúrgicos, configurados a partir de outras características do paciente (idade, diagnóstico secundário, comorbidades e complicações, dentre outras) que afetam o tempo de permanência do paciente no hospital e, portanto, o seu custo.

O sistema de pagamento prospectivo por procedimento requer, além de um método de classificação dos pacientes adequado ao custo dos tratamentos neles efetuados, um sistema de definição dos preços unitários das altas que leve em conta características do hospital que também afetam seus custos (principalmente, seus custos fixos), tais como seu nível de complexidade e o fato de ser ou não um hospital de ensino, dentre outros. seguinte forma:

Nesse sentido, nos EUA o sistema de pagamento prospectivo se dá da

- a cada grupo de DRG corresponde um determinado número de pontos, $\mathrm{P}(\mathrm{i})$;

- a cada hospital corresponde uma tarifa unitária, T(h);

4 Existem vários outros métodos de classificação dos pacientes; mencionamos apenas o dos DRGs pois ele é o adotado até hoje pelo programa MEDICARE para o pagamento das internações efetuadas por hospitais da rede contratada. 
- o valor pago por cada internação é igual a $\mathrm{P}(\mathrm{i}) \mathrm{x} \mathrm{T}(\mathrm{h})$, isto é, ao produto do número de pontos do DRG correspondente multiplicado pela tarifa unitária do hospital.

Além disso, estão previstos pagamentos diferenciados para pacientes outliers, que fogem do padrão estabelecido nos DRGs.

Apesar desses cuidados, no sentido de estabelecer preços que levem em conta as diferenças dos pacientes (expressas em sua classificação nos DRGs) e as diferenças dos custos fixos dos hospitais, segundo seu tipo (expressas na definição das tarifas unitárias diferenciadas), inúmeros problemas foram detectados nos EUA, relatados por Ugá (1996).

Nesse país, a experiência mostrou que, tendo em vista que o sistema remunera os hospitais segundo valores pré-fixados, que independem do custo efetivo de cada internação, o sistema tem levado à redução dos insumos e serviços intermediários utilizados em cada internação (necessários ou não), ou seja, à alteração de suas funções de produção com o intuito de diminuírem o custo das internações (GAY et al, 1989). Também foi observado o aumento das reinternações, o qual sugere que altas precoces foram dadas, com o intuito de reduzir custos e/ou gerar novas internações a serem remuneradas (CHULIS, 1991; FEINGLASS \& HOLLOWAY, 1991; HORNBROOK \& BERKI, 1985). Outro fenômeno apontado por vários autores, dentre os quais Carter et al (1990), foi o da atribuição, aos pacientes internados, de DRGs que não correspondiam exatamente ao seu perfil, e sim a grupos de mais alta pontuação, no fenômeno denominado de DRG creep. Finalmente, de acordo com Guterman e Dobson (1986), pode-se supor que o método de pagamento prospectivo por procedimento leve a uma mudança das prioridades dos prestadores, na qual se subordine a preocupação com a qualidade a objetivos meramente financeiros.

De todas as formas, este método vem sendo progressivamente incorporado em vários sistemas de saúde (Portugal, Espanha, dentre outros), porque se espera dele a indução à contenção dos custos unitários das internações hospitalares e, assim, a redução do gasto em saúde. Da mesma forma, os sistemas de classificação de pacientes (dentre os quais o dos DRGs) vêm sendo há muitos anos adotados em países como Irlanda para a construção do orçamento dos hospitais a partir do case-mix ${ }^{5}$ desses prestadores.

\subsection{4| Considerações adicionais}

Evidentemente, nenhum modelo tradicional de alocação ou pagamento consegue conciliar a previsibilidade de receitas e despesas e a desvinculação do paciente

5 O case-mix corresponde ao perfil da produção do hospital, segundo grupos de classificação de pacientes e sua respectiva frequência na produção hospitalar. 
de algum preço (como é o caso dos sistemas de alocação de recursos por orçamento global e por capitação) com o estímulo a um melhor desempenho do prestador de serviços de saúde, tanto em termos quantitativos (como o faz o pagamento prospectivo por procedimento) como qualitativos (aspecto não alcançado por nenhum dos métodos tradicionais de alocação de recursos).

Na busca por melhores alternativas, alguns países vêm incorporando soluções distintas, seja através de sistemas mistos, seja através do pagamento por desempenho (payment for performance), seja através de outras propostas. Esse é o objeto da seção que segue.

\section{3 | SISTEMAS ALTERNATIVOS ENCONTRADOS NA EXPERIÊNCIA INTERNACIONAL}

Os países da OCDE têm-se debruçado nos últimos anos fundamentalmente sobre sistemas para alocação de recursos a hospitais, tendo em vista que o gasto hospitalar consumiu em 2008, em média, um terço do gasto em saúde nos países da OCDE e, em alguns países europeus, chega a representar nada menos que 70\% desse gasto (CYLUS \& IRWIN, 2010). Entretanto, abaixo são apresentadas experiências que se referem, em alguns casos, à alocação de recursos para a atenção primária.

\section{1 | Sistemas Mistos}

Alguns países, tais como Espanha, Portugal, França, Alemanha, Holanda e Suíça, dentre outros, adotaram no final dos anos noventa ou início da atual década sistemas mistos de alocação de recursos aos prestadores de serviços de saúde.

Assim, enquanto os três últimos associaram o orçamento global ao pagamento por diária hospitalar, Portugal e algumas províncias espanholas adotaram sistemas compostos por orçamento global e pagamento prospectivo por DRG.

Na França, por exemplo, os hospitais públicos foram nos anos noventa financiados mediante orçamento global, acrescido de um pagamento por diária, do qual 20\% incide sobre o paciente (em função disso, existe um mercado de seguros especificamente em relação a este elevado copagamento). Note-se que o valor da diária varia segundo o serviço e o tipo de hospital. Atualmente, esse país adotou o pagamento prospectivo por procedimento.

Na Alemanha, aos hospitais públicos é atribuído um orçamento global negociado com o fundo financiador; entretanto, a alocação final de recursos é realizada através de pagamento por diária hospitalar. 
Por sua vez, a Holanda atribui aos hospitais públicos um orçamento global que estabelece o montante total anual a ser recebido por cada hospital, em base ao tamanho da população a ser atendida, à capacidade instalada contratada (leitos segundo especialidades) e à produção contratada (número de internações, consultas e hospital-dia). Entretanto, assim como na Alemanha, a alocação efetiva de recursos é feita através de pagamento por diária hospitalar.

Algumas províncias espanholas - como Catalunha e Valencia- adotaram no final dos anos noventa um sistema misto para a alocação de recursos aos hospitais públicos. Um orçamento global estabelece o montante total anual a ser recebido por cada hospital, em base ao seu case-mix. Entretanto, a alocação de recursos se deu de forma composta: 65\% dos recursos orçados são alocados de forma global, enquanto 35\% dos mesmos são transferidos através de pagamento prospectivo por procedimento, adotando o sistema de classificação dos pacientes por DRG. Novas formas de alocação de recursos são adotadas na atualidade em algumas províncias espanholas e serão apresentadas abaixo.

Portugal foi o primeiro país a adotar a composição orçamento global e pagamento por DRG: mediante orçamento global é estabelecido o montante total anual a ser recebido por cada hospital, em base ao perfil de sua produção, isto é, seu casemix. Mas a efetiva alocação de recursos é feita crescentemente (40\% em 2001) através de pagamento prospectivo por procedimento (DRG). Atualmente, novas experiências estão sendo desenvolvidas e serão discutidas em outra seção deste documento.

Como evidenciado em Schreyogget al (2006), o método de atribuição de valores aos DRGs varia muito de um país a outro. Entretanto, pode-se sintetizar a situação da Europa no quadro abaixo, no qual se verifica que grande parte dos países utiliza sistemas mistos.

Quadro 01. Métodos de alocação de recursos a hospitais e gasto hospitalar em países europeus

\begin{tabular}{|c|c|c|c|}
\hline Países & $\begin{array}{l}\text { Gasto hospitalar } \\
\text { como \% gasto } \\
\text { em saúde }\end{array}$ & $\begin{array}{c}\text { Gasto hospitalar } \\
\text { per capita } \\
\text { (US\$ PPP) }\end{array}$ & $\begin{array}{l}\text { Sistema de alocação de recursos a } \\
\text { hospitais }\end{array}$ \\
\hline Áustria & $38,8 \%$ & 1.393 & PPP* + reembolso retrospectivo dos custos \\
\hline Alemanha & $29,4 \%$ & 1.061 & Orçamento global + PPP \\
\hline Bélgica & $31,2 \%$ & 1.147 & $\begin{array}{r}\mathrm{PPP}+\text { pagamento por ato + pagamento para } \\
\text { medicamentos }\end{array}$ \\
\hline Dinamarca & $46,2 \%$ & 1.567 & Orçamento global + PPP \\
\hline Espanha & $39,8 \%$ & 1.117 & Orçamento por linha de cuidado \\
\hline Eslováquia & $26,7 \%$ & 442 & PPP \\
\hline Eslovênia & $41,6 \%$ & & 918 \\
\hline
\end{tabular}


Quadro 01. Métodos de alocação de recursos a hospitais e gasto hospitalar em países europeus (cont.)

\begin{tabular}{|c|c|c|c|}
\hline Países & $\begin{array}{c}\text { Gasto hospitalar } \\
\text { como \% gasto } \\
\text { em saúde }\end{array}$ & $\begin{array}{c}\text { Gasto hospitalar } \\
\text { per capita } \\
\text { (US\$ PPP) }\end{array}$ & $\begin{array}{l}\text { Sistema de alocação de recursos a } \\
\text { hospitais }\end{array}$ \\
\hline Estônia & $46,5 \%$ & 563 & PPP \\
\hline Finlândia & $35,3 \%$ & 1.010 & PPP \\
\hline França & $35,0 \%$ & 1.259 & PPP \\
\hline Holanda & $37,0 \%$ & 1.378 & Orçamento global + PPP \\
\hline Hungria & $33,1 \%$ & 463 & PPP \\
\hline Islândia & $40,6 \%$ & 1.363 & Orçamento global \\
\hline Noruega & $38,2 \%$ & 1.613 & Orçamento global + pagamento por ato \\
\hline Polônia & $34,5 \%$ & 391 & PPP \\
\hline Portugal & $37,5 \%$ & 796 & Orçamento global \\
\hline Reino Unido & $s / d$ & $s / d$ & Orçamento global + PPP \\
\hline República Tcheca & $45,8 \%$ & 796 & Orçamento global + PPP + por ato \\
\hline Suécia & $46,9 \%$ & 1.545 & Orçamento global + PPP \\
\hline Suíça & 35,1 & 1.567 & Orçamento global + PPP \\
\hline
\end{tabular}

(*) Pagamento Prospectivo por Procedimento (PPP).

Fonte: Extraído de: Cylus\& Irwin, Euro Observer, 2010.

\subsection{O Pagamento por Desempenho (Payment for Performance)}

Este modelo de alocação de recursos se insere nas reformas dos sistemas de saúde que vêm sendo implementadas em vários países da OCDE desde o final dos anos noventa, com o intuito da redução dos custos globais do sistema de saúde e o aumento da eficiência dos prestadores, bem como da efetividade dos serviços de saúde.

Elas envolvem ações que incidem sobre a demanda de serviços de saúde e outras sobre a oferta dos mesmos, sob a égide do modelo do gerencialismo. Assim, por um lado, foram introduzidos mecanismos de gestão da demanda, tais como a introdução de médicos de porta de entrada ao sistema de saúde (gatekeepers) e de mecanismos de copagamento ou de coparticipação nos custos dos serviços. Por outro, foram desenvolvidas diversas formas de contratualização de serviços de saúde pelos gestores do sistema, às quais corresponderam modalidades de alocação de recursos segundo o desempenho do prestador, medido em termos do cumprimento de metas quantitativas e qualitativas. Mais recentemente, se destaca uma preocupação com a gestão da incorporação tecnológica e, assim, as metas -em alguns países- incluem a definição do tipo de tecnologia a ser adotada, em busca da obtenção de mais valor 
através dos recursos aplicados, conceito esse mais difundido na literatura em inglês sob a denominação de value for money (DOCTEUR, 2004).

O pagamento por desempenho (payment for performance) não é, em si mesmo, um sistema de alocação de recursos (KAZANDJIAN, 2010); na realidade, ele ajusta o montante de recursos a ser alocado (através de algum método tradicional, em geral por orçamento global ou por capitação e, em alguns casos, o pagamento prospectivo por procedimento) ao prestador de serviços de saúde, segundo o seu desempenho, medido em termos de indicadores que podem ser de estrutura, de processo ou de resultados e, ainda, quantitativos ou qualitativos.

No Reino Unido, no contexto do gerencialismo, foram estabelecidos contratos que continham incentivos financeiros para a melhoria do desempenho no programa de imunizações e em atividades de promoção da saúde, dentre outras (CHRISTIANSON et al, 2007). Esse movimento se intensificou nos anos 2000, destinandose recursos adicionais de um bilhão de libras ao NHS para o pagamento de incentivos ao aumento da qualidade (ROLAND, 2004).

Nesse programa, os clínicos gerais que atuam como porta de entrada no sistema - GPs — podiam receber uma remuneração adicional de até 42 mil libras por médico referente ao cumprimento de metas qualitativas. Esse novo modelo de contrato entre o Estado e os GPs, que contempla incentivos ao aumento da qualidade na atenção médica, associa nada menos que $25 \%$ da remuneração dos clínicos gerais ao seu desempenho. Este é medido através de 146 indicadores pertencentes aos seguintes domínios (Christianson et al, op.cit.):

- padrões clínicos relacionados ao cuidado de pacientes;

- padrões organizacionais referentes ao registro e à informação, comunicação com os pacientes, educação e treinamento, gestão dos medicamentos, gestão clínica;

- experiência do paciente, baseada em inquéritos e consultas;

- serviços adicionais (acompanhamento da saúde infantil, de serviços de pré-natal e contracepção, dentre outros).

- cuidado holístico, baseado no desempenho no domínio clínico.

Vale mencionar que, no Sistema Nacional de Saúde inglês, o sistema de pagamento por desempenho qualitativo (pay for performance - P4P) foi aplicado inicialmente aos gestores de microssistemas de saúde como os GPs e, a partir de 2004, aos então criados Primary Care Trusts. Ele foi aplicado, depois, também a hospitais; o orçamento destinado a cada um era ajustado segundo o cumprimento de metas de qualidade assistencial e este era aferido a partir de indicadores definidos no Quality and 
Outcomes Framework. Estes indicadores dizem respeito, fundamentalmente, a processos utilizados no tratamento de alguns agravos (asma, diabetes, cardiopatia isquêmica, câncer, dentre outros) ${ }^{6}$ definidos com a colaboração do National Institute for Clinical Excellence (NICE).

Este modelo vem sendo também aplicado em Portugal, também, para a alocação de recursos às Unidades de Saúde Familiar (USF), no âmbito da atenção primária (AFONSO, 2010). Nesse país, o desempenho é aferido a partir de indicadores de acesso e utilização de serviços, adequação do cuidado, qualidade percebida pelos pacientes e eficiência econômica, no contexto de contratualização dos serviços de atenção primária, mas ainda não há experiência acumulada que permita fazer uma avaliação do seu impacto sobre o desempenho do sistema de saúde.

Isso foi possível na Inglaterra, que acumula uma experiência mais longa do pagamento ajustado por desempenho. Assim, Campbell et al (2009) desenvolveram recentemente um estudo sobre os efeitos dessa forma de alocação de recursos sobre a qualidade da atenção primária nesse país. O trabalho compara os dois anos prévios à implementação do sistema com dois anos posteriores à mesma e mostra que os indicadores de qualidade referidos à atenção de pacientes com asma, diabetes e

6 Por exemplo, no que se refere à atenção a pacientes com cardiopatia isquêmica, foram definidos os seguintes indicadores de registro de pacientes, diagnóstico e tratamento:

\section{Records}

CHD 1. The practice can produce a register of patients with coronary heart disease

Diagnosis and initial management

CHD 2. The percentage of patients with newly diagnosed angina (diagnosed after 1 April 2003) who are referred for exercise testing and/or specialist assessment

\section{Ongoing Management}

CHD 3. The percentage of patients with coronary heart disease whose notes record smoking status in the past 15 months, except those who have never smoked where smoking status need be recorded only once since diagnosis

CHD 4. The percentage of patients with coronary heart disease who smoke, whose notes contain a record that smoking cessation advice or referral to a specialist service, where available, has been offered within the last 15 months

CHD 5. The percentage of patients with coronary heart disease whose notes have a record of blood pressure in the previous 15 months

CHD 6. The percentage of patients with coronary heart disease in whom the last blood pressure reading (measured in the last 15 months) is 150/90 or less

CHD 7. The percentage of patients with coronary heart disease whose notes have a record of total cholesterol in the previous 15 months

CHD 8. The percentage of patients with coronary heart disease whose last measured total cholesterol (measured in last 15 months) is $5 \mathrm{mmol} / \mathrm{l}$ or less

CHD 9. The percentage of patients with coronary heart disease with a record in the last 15 months that aspirin, an alternative anti-platelet therapy, or an anti-coagulant is being taken (unless a contraindication or side-effects are recorded)

CHD 10. The percentage of patients with coronary heart disease who are currently treated with a beta blocker (unless a contraindication or side-effects are recorded)

CHD 11. The percentage of patients with a history of myocardial infarction (diagnosed after 1 April 2003) who are currently treated with an ACE inhibitor or Angiotensin II antagonist

CHD 12. The percentage of patients with coronary heart disease who have a record of influenza immunisation in the preceding 1 September to 31 March

Ver a esse respeito: (http://www.dh.gov.uk/prod_consum_dh/groups/dh_digitalassets/@dh/@en/documents/ digitalasset/dh_4088693.pdf) 
cardiopatia isquêmica já haviam melhorado (no caso dos dois primeiros) em período prévio ao pagamento por desempenho e continuaram exibindo melhores resultados - embora com uma melhora mais lenta- após a implantação do P4P. Diferentemente, mostra o mesmo estudo que se observaram pioras nos indicadores de atenção à cardiopatia isquêmica. Peiró (2009) comenta o artigo, levantando a hipótese de que depois de um período de melhora nos indicadores, seja mais difícil manter o ritmo de crescimento desses resultados e/ou que o sistema de pagamento por desempenho não estimule a continuidade de melhorias uma vez alcançadas as metas mínimas estabelecidas pela autoridade sanitária.

Christianson et al. (2007) revisaram 36 artigos publicados sobre os impactos desses incentivos financeiros sobre a qualidade dos serviços prestados. Encontraram escassas avaliações de um impacto significativo e destacam a dificuldade de avaliar programas com desenhos muito distintos. Estimam, ainda, que a limitação do impacto desses incentivos financeiros é provavelmente devida, em alguns casos, ao fato de que um mesmo prestador possui distintos vínculos / contratos com órgãos financiadores diversos.

Outras limitações detectadas se referem à mensuração do desempenho: o número pequeno de pacientes portadores de determinados agravos (diabetes, p.ex.) tratado por cada médico; o fato de que os melhores médicos tratam, em geral, dos casos mais complexos (o que leva à necessidade de avaliar o desempenho ajustado por risco) e, enfim, a complexidade de um processo de avaliação de desempenho, o qual, por sua vez, introduz custos adicionais ao sistema.

No início dos anos noventa, também nos EUA algumas operadoras de planos de saúde (Health Maintenance Organizations - HMO) introduziram nos seus contratos com os prestadores incentivos pecuniários para que metas qualitativas fossem atingidas, adotando o sistema de benchmarking.

A experiência norte-americana de pagamento por desempenho qualitativo da atenção destinada a pacientes com infarto agudo do miocárdio, insuficiência cardíaca e pneumonia foi avaliada por Grossbart (2006). Nesse estudo, foram comparados quatro hospitais de uma organização sem finalidade de lucro pagas por desempenho com outros seis da mesma organização (grupo controle) que não aderiram a essa forma de remuneração. $\mathrm{O}$ artigo mostra que o grupo de hospitais pagos por desempenho exibiu maiores scores de qualidade nas três áreas clínicas estudadas, bem como um indicador global de qualidade mais satisfatório. Assim, o grupo teste conseguiu um indicador de qualidade $(89,7 \%)$ bastante superior ao do grupo controle $(85,6 \%)$. Vale mencionar que os indicadores de qualidade utilizados dizem respeito aos processos adotados pelos prestadores. 
Estes dois estudos, bem como outros trabalhos ${ }^{7}$, evidenciam que existe algum impacto do sistema de pagamento por desempenho sobre a qualidade da atenção à saúde, porém menor do que o desejável. Um fator que talvez explique, pelo menos em parte, esses resultados refere-se ao fato de que, na maior parte dos países que experimentaram esse modelo de alocação de recursos, os indicadores de desempenho qualitativo a partir dos quais são avaliados os prestadores referem-se, na sua maior parte, a processos da prática médico-assistencial e não a resultados sobre a saúde da população.

Vale mencionar a esse respeito Maynard (op.cit.), ao afirmar que "o corolário da gestão do desempenho é a mensuração dos resultados sobre a saúde dos pacientes". Isso envolve, segundo o autor, não somente dados de mortalidade, mas também índices que retratam qualidade de vida dos pacientes antes e depois da assistência à sua saúde. Ainda, como afirma Ortún (2005 e 2009), é necessário introduzir medidas de resultado e de qualidade clínica para "reduzir a distância entre eficácia e efetividade nos serviços de saúde" .

\subsection{Do Volume ao Valor}

A discussão internacional mais recente aponta para o fato de que a maior parte dos sistemas de alocação de recursos adotados na atualidade encoraja muito mais o aumento do volume dos serviços prestados do que o valor agregado desses serviços, em termos de ganhos no estado da saúde da população, como destacado no NRHI Healthcare Payment Reform Summit (2008).

Nesse encontro, salientou-se a necessidade de dotar de mais responsabilidade os prestadores de serviços de saúde no que concerne ao aumento da qualidade e controle dos custos, sem penalizá-los quando tratam de pacientes mais complicados. E identificaram a necessidade de alocar recursos diferenciadamente segundo se tratasse da atenção a pessoas portadoras de condições crônicas (majoritariamente prestada pelo primeiro nível de atenção, embora de forma não exclusiva) ou quando se tratasse de tratamentos efetuados em casos agudos. Note-se que pessoas portadoras de condições crônicas podem apresentar episódios agudos.

A atenção a episódios agudos deveria ser, segundo essa proposta, remunerada através do "pagamento por episódio de cuidado" (episode-of-carepayment) - que consiste no estabelecimento de um único preço ou valor por todos os serviços requeridos para o tratamento desses casos, tais como infarto agudo do miocárdio, por exemplo. Para isso, seria alocado por paciente tratado um único valor global que incluiria

\footnotetext{
7 Giuffridaet al (2000); Tannenbaum (2009).

8 Tradução livre.

9 Tradução livre.
} 
a remuneração de todos os prestadores envolvidos no cuidado (SADT, honorários médicos, serviços hospitalares, etc.). Isso pressupõe a existência de uma entidade que receberia esse único pagamento e se responsabilizaria por remunerar todos os prestadores envolvidos, ou seja, requereria a existência de gestores de microssistemas constituídos por redes organizadas de prestadores de todos os níveis de atenção.

No que concerne à atenção primária destinada a pessoas portadoras de condições crônicas, propõe-se, diferentemente, a alocação de recursos por capitação, baseada em um valor per capita ajustado por risco, para que o prestador seja responsável por mantê-los em boas condições de saúde (e evitar internações), segundo os princípios da atenção centrada no paciente (patient-centered medical home).

A proposta ainda contempla o estímulo aos pacientes no sentido de utilizarem prestadores mais eficientes, ou seja, que prestem uma assistência de boa qualidade a um menor custo do que outros, o qual reforça a necessidade de constituir redes integradas de prestadores de serviços de saúde.

Nessa mesma direção se encontra a proposta da alocação de recursos por caso (crônico) gerido, no contexto da gestão integrada da doença. Na literatura portuguesa, esse modelo de alocação de recursos é denominado "pagamento por preço compreensivo" (ESCOVALET al, 2010) que, segundo esses autores, corresponde a um valor médio por paciente por um determinado período de tempo, que "engloba o conjunto de atos clínicos, medicamentos e outras atividades consideradas essenciais para uma adequada prestação de cuidados". Todavia, a efetivação da alocação de recursos depende, nessa proposta do cumprimento de parâmetros de qualidade e segurança do paciente, aferidos através de um conjunto de indicadores de resultados.

Esse modelo pressupõe a existência de um prestador responsável pela gestão da linha de cuidados requeridos por cada grupo de pacientes e, assim, responsável pelo pagamento a outros prestadores, situados em distintos níveis de atenção. No caso português, este modelo começa a ser experimentado através da instituição dos Centros de Elevada Diferenciação (CED), entendidos como unidades que desenvolvem competências clínicas e de investigação e estruturam o cuidado integral dos pacientes. O modelo requer, ainda, a estruturação de redes integradas de serviços, a serem geridas ou contratualizadas por esses centros.

\section{4 | Apreciação Geral}

Uma apreciação mais global da experiência internacional mostra as seguintes tendências:

- os métodos tradicionais de alocação de recursos foram substituídos por sistemas mistos ou complementados pelo ajuste por desempenho; 
- a alocação de recursos ajustada por desempenho requer, para ser mais eficaz, a adoção de indicadores de desempenho que, para além de medirem processos assistenciais e de gestão (essencialmente à eficiência e qualidade), se refiram predominantemente a resultados sobre a saúde da população, ou seja à efetividade da atuação dos serviços de saúde;

- nesse sentido, percebe-se uma tendência a adotar sistemas de alocação de recursos destinados a centros de atenção primária responsáveis pela saúde da população de um dado território que, se necessário, contratarão serviços de outros níveis de atenção;

- em decorrência disso, concebe-se a alocação de recursos por linhas de cuidado, por gestão da doença ou, nos termos portugueses, por "preço compreensivo", destinada aos responsáveis por essa gestão do cuidado, geralmente em mãos da atenção primária;

- dessa forma, propugnam-se modalidades distintas de alocação de recursos para a atenção primária (em base à capitação, ajustada por risco, por desempenho ou por algum outro critério) e para os hospitais, a serem remunerados por orçamento global ajustado por desempenho (qualitativo e quantitativo) ou por pagamento prospectivo por procedimento, dependendo do país de que se trate.

\section{4 | O CASO BRASILEIRO}

\subsection{Métodos predominantes de alocação de recursos no setor público}

No setor público brasileiro, usava-se até o início dos anos noventa predominantemente o orçamento global para a alocação de recursos por aos prestadores de serviços de saúde públicos. Ainda, até 1983, o antigo INAMPS ${ }^{10}$ pagava a rede contratada de prestadores privados por ato médico (através das Guias de Internação Hospitalar, tão criticadas à época em função do superfaturamento que propiciaram através da apresentação de faturas que continham atos e procedimentos não necessariamente realizados). A partir desse ano, o INAMPS passou a adotar o sistema de pagamento prospectivo por procedimento para remunerar a rede privada por ele contratada.

10 Instituto Nacional de Assistência à Saúde da Previdência Social 
Com o advento do SUS, extinguiu-se o INAMPS e o Ministério da Saúde passou a ser o contratante da rede privada de hospitais que atuam no sistema público brasileiro (e representam até hoje quase 60\% dos leitos hospitalares ofertados pelo SUS), mantendo o sistema de pagamento prospectivo por procedimento, operacionalizado através das Autorizações para Internação Hospitalar (AIH). Até 1991, o Ministério continuou alocando recursos aos hospitais públicos mediante orçamento global.

Uma grande mudança ocorre no início dos anos noventa, no Governo Collor de Melo, quando o sistema de pagamento prospectivo por procedimento passa a ser adotado pelo Ministério da Saúde também para as unidades públicas: os hospitais passaram a ser remunerados segundo o volume e tipo de sua produção através das mesmas AIHs e as unidades ambulatoriais passaram a receber recursos de acordo à produção por elas apresentada, classificada segundo o Sistema de Informações Ambulatoriais do SUS (SIA-SUS).

Vale notar que, embora o SIA-SUS tenha sido apresentado, à época, como um sistema similar ao da AIH, ele não o é, tendo em vista que a lista de serviços ambulatoriais que consta no SIA-SUS nada mais é do que um conjunto de atos médicos. Este sistema foi defendido por alguns autores que o viam como uma forma de garantir a informação sobre a produção hospitalar e ambulatorial, mas muito criticado por alguns autores, levando em conta diversos motivos ${ }^{11}$.

11 Como já apontado em Ugá (1992), o sistema de pagamento prospectivo por procedimento adotado no Brasil contém, desde a sua concepção, inúmeros e sérios problemas apresentados a seguir. Vale lembrar que este sistema requer, por um lado, um sólido método de classificação dos pacientes que corresponda ao custo dos tratamentos neles efetuados e, por outro, um sistema de definição dos preços unitários que leve em conta, além do tipo de paciente tratado (e os custos variáveis deles decorrentes), certas características do hospital que também afetam seus custos fixos. O sistema concebido em 1981 e implementado em 1983 no Brasil apresenta importantes deficiências tanto no que se refere ao sistema de classificação dos pacientes como no método de cálculo dos valores correspondentes a cada grupo diagnóstico. Antes de ser implementado em nível nacional para pagamento ao setor privado através do Sistema de Assistência Médico-Hospitalar da Previdência Social (SAMHPS), ele passou por uma fase experimental, conhecida como Projeto Curitiba, em 1981, na qual foi aplicada uma tabela de valores (ou preços) elaborada da seguinte forma (UGÁ, 1994, op.cit.): constituiu-se uma primeira classificação dos procedimentos hospitalares, em 2300 grupos diagnósticos, com base em informações de mais de oito milhões de internações realizadas em 1980 no Brasil e pagas por ato médico (GIH) e, depois, para efeitos de maior facilidade operacional, essa lista foi reduzida de 2300 para 260 grupos. Esta nova lista de procedimentos, como relatam Chiyoshi e Moura (s/d), baseou-se fundamentalmente na experiência médica e administrativa de uma equipe de médicos que participaram ativamente da implantação e operação do sistema no estado do Paraná, dispensando-se a utilização de sofisticados recursos estatísticos e computacionais nos moldes do Sistema DRG. Dessa forma, não só partiu-se de uma base de informações distorcidas (os registros de pagamento por GIH que, pelo alto nível de fraudes que possibilitava, foi substituído pelo sistema de pagamento por AIH), como também esses precariamente construídos 2300 grupos diagnósticos foram reclassificados em 260, de uma forma muito pouco rigorosa. Por outro lado, no que se refere à definição de valores a serem atribuídos a cada grupo diagnóstico, o sistema também apresenta fragilidades, pois o preço a ser pago por AIH era constituído de 4 componentes - Diárias e taxas; Serviços Auxiliares de Diagnóstico e Terapia; Materiais e Medicamentos; Serviços Profissionais - que, durante alguns anos da vigência da AIH, tiveram seus reajustes definidos de forma distinta, conforme o poder de pressão do setor que os negociava com o INAMPS: os dois primeiros componentes eram reajustados segundo critérios do INAMPS, enquanto o de Materiais e Medicamentos era negociado com a poderosa ABIFARMA e o de Serviços Profissionais guardava proporcionalidade com o Coeficiente de Honorários da Associação Médica Brasileira. Desse modo, com o passar do tempo, procedimentos cuja AIH tivesse como componente mais importante o de Materiais e Medicamentos, por exemplo, tenderiam a sofrer reajustes mais expressivos do que outros procedimentos, nos quais as Diárias e Taxas e Serviços Auxiliares de Diagnóstico 
A partir da NOB-96 e, principalmente, da instituição do Pacto pela Saúde, são as Secretarias Estaduais e Municipais que passaram progressivamente a alocar recursos aos prestadores de sua jurisdição. Nesse momento, passam a coexistir no Brasil distintas modalidades de alocação de recursos aos prestadores hospitalares e ambulatoriais, que variam segundo a realidade estadual ou municipal. Algumas dessas modalidades serão apresentadas a seguir. Entendemos, no entanto, que o elenco de alternativas abordado não contempla todas as realidades existentes no conjunto de mais de cinco mil municípios brasileiros.

As principais formas de alocação de recursos pelo Ministério da Saúde no âmbito do SUS em vigor atualmente são as seguintes:

- Hospitais próprios do Ministério da Saúde (MS): a alocação de recursos aos hospitais próprios do MS se dá através de um orçamento global e têm autonomia para realizar compras de materiais e de serviços. Ainda assim, eles são obrigados a alimentar o Sistema de Informações Hospitalares e o Sistema de Informações Ambulatoriais (SIH-SUS e SIA-SUS);

- Hospitais de ensino próprios de instituição federal ou estadual de ensino superior: a situação varia segundo eles estejam ou não inseridos na política de contratualização do MS: os contratualizados são remunerados através de um sistema misto de alocação de recursos, que será apresentado abaixo; os não contratualizados recebem recursos do SUS através do método de pagamento por procedimento, mediante o sistema SIH-SUS e SIA-SUS.

- Hospitais de pequeno porte (até 30 leitos): a situação varia segundo eles estejam ou não inseridos na política de contratualização do MS: os contratualizados são remunerados através de orçamento global ajustado por desempenho, que será apresentado abaixo; os não contratualizados recebem recursos do SUS através do método de pagamento por procedimento, mediante o sistema SIH-SUS e SIA-SUS.

\footnotetext{
e Terapia (definidos exclusivamente pelo INAMPS) fossem os predominantes no cálculo do valor da AIH Atualmente, os reajustes são calculados em relação ao valor global da AIH, mas, ainda assim, a periodicidade do reajuste (bem como o percentual) não é o mesmo para todas as AIHs, variando segundo o poder de pressão de cada grupo de prestadores privados. Portanto, como analisado em Ugá (1992, op.cit.), passaram a existir procedimentos lucrativos e outros deficitários e, portanto, pacientes lucrativos e outros que geram déficit, o qual leva a um movimento de segregação destes últimos. Ainda, afirmávamos que o sistema de pagamento prospectivo por procedimento transforma o produto sanitário (seja ele prestado por unidades públicas ou privadas) em uma mercadoria colocada no mercado de serviços de saúde. Ademais, em relação a este sistema em que o preço é pré-fixado e não é possível estocar produtos (...), na esfera da produção, o produto sanitário é o tratamento, que se transforma - na esfera da circulação- no paciente a ser (ou não) tratado.
} 
- Hospitais filantrópicos: a situação varia segundo eles estejam ou não inseridos na política de contratualização do MS: os contratualizados são remunerados através de um sistema misto de alocação de recursos, que será apresentado abaixo; os não contratualizados recebem recursos do SUS através do método de pagamento por procedimento, mediante o sistema SIH-SUS e SIA-SUS.

- A rede hospitalar privada com fins lucrativos contratada pelo SUS: a rede privada de hospitais que atuam no SUS recebe recursos através do sistema de pagamento prospectivo por procedimento, operacionalizado através dos sistemas $\mathrm{AIH}$ e SIA-SUS.

Estas modalidades de contratualização e alocação de recursos implementadas pelo Ministério da Saúde, bem como outras desenvolvidas por secretarias estaduais e municipais de saúde são apresentadas a seguir.

\subsection{Modalidades de Alocação de Recursos Adotadas em Modelos de Contratualização}

No Brasil, modalidades de alocação de recursos condicionada ao desempenho de hospitais e de unidades de atenção básica e/ou equipes profissionais têm sido experimentadas, por iniciativas do governo federal e de alguns governos estaduais e municipais, através do uso de modelos de contratualização.

Não há ainda um mapeamento destas experiências no país, entretanto possivelmente as experiências mais antigas, estruturadas e documentadas são a política de contratualização do Ministério da Saúde/MS destinada a determinados segmentos do parque hospitalar no país, os contratos de gestão entre a Secretaria Estadual de Saúde de São Paulo/SES/SP e as Organizações Sociais de Saúde/OSS para gerenciar equipamentos de saúde da Secretaria, os Termos de Compromisso dos hospitais públicos, estatais e filantrópicos, do Programa Hospitalar/PROHOSP e das equipes de saúde da família na atenção básica, da Secretaria Estadual de Saúde de Minas Gerais/ SES/MG, e os contratos de gestão ou Termos de Compromissos utilizados na atenção básica pela Secretaria Municipal de Saúde de Curitiba.

\subsection{1 | A política de contratualização do MS}

A política de contratualização do MS, implementada a partir de 2004/2005, pela Coordenação-Geral da Atenção Hospitalar (CGAT) do Departamento 
de Atenção Especializada (DAE) da Secretaria de Atenção à Saúde (SAS) do Ministério da Saúde (MS), focaliza três grupos de hospitais: os hospitais de ensino/HE (neste caso em parceria com o Ministério da Educação/MEC), os hospitais filantrópicos/HF e os hospitais de pequeno porte/HPP. A contratualização integra as Políticas/Programas de Reestruturação desses hospitais e constitui-se no instrumento que pretende assegurar a implantação um conjunto de diretrizes e metas que visam à qualificação assistencial e gerencial, a uma maior inserção desses hospitais na rede de serviços -inclusive se necessário com ajuste no perfil assistencial- e, no caso dos hospitais de ensino, considera, ainda, um conjunto de ações no campo do ensino da graduação e pós-graduação, da educação permanente e formação de profissionais de saúde e também em pesquisa e avaliação tecnológica em saúde, tendo em vista as demandas do Sistema Único de Saúde/SUS.

\section{O Programa de reestruturação dos hospitais de ensino no SUS}

Foram constituídos dois Programas de Reestruturação dos Hospitais de Ensino, um envolvendo os hospitais das instituições federais de ensino superior (Brasil. Portaria Interministerial no 1006/MEC/MS, de 27/05/2004) e o outro abarcando os demais hospitais de ensino de natureza pública ou privada no SUS (Brasil. Portaria Interministerial no 1702/GM, de 17/08/2004).

Para ingressar no Programa há uma condição obrigatória que antecede a contratualização: a certificação. Somente após os hospitais serem certificados como de ensino, por uma comissão interinstitucional constituída exclusivamente para tal finalidade, eles podem ingressar no Programa por solicitação do secretário municipal ou estadual de saúde, na dependência de ser gestor pleno da rede de atenção. A certificação, solicitada pelo dirigente do HE junto ao MS e MEC, estabelece 17 critérios claros e precisos, até então inexistentes, nos campos da assistência, gestão, ensino e pesquisa para o hospital ser considerado de ensino ${ }^{12}$.

12 A Portaria Interministerial no 2400/MEC/MS, de 02/10/2007, estabelece no seu Art. 7 o a obrigatoriedade dos seguintes requisitos para que as unidades hospitalares sejam certificadas como Hospitais de Ensino: I — abrigar, formalmente e em caráter permanente e contínuo, todos os alunos de, pelo menos, um curso de medicina, em atividades curriculares de, no mínimo, uma área integral do internato, além de atividades curriculares dos alunos de pelo menos dois outros cursos de graduação na área da saúde, e as unidades hospitalares especializadas que não dispuserem de internato deverão abrigar curso de pós-graduação stricto sensu devidamente reconhecido pela Coordenação de Aperfeiçoamento de Pessoal de Nível Superior (CAPES); II abrigar, em caráter permanente e contínuo, programas de Residência Médica regularmente credenciados pela Comissão Nacional de Residência Médica (CNRM), observando: a) no caso de hospitais gerais oferecer o número mínimo de vagas definido no Anexo III a esta Portaria para entrada de novos residentes em, pelo menos, duas áreas básicas de formação (Cirurgia Geral, Clínica Médica, Ginecologia e Obstetrícia, Medicina de Família e Comunidade ou Pediatria); b) que hospitais especializados devem oferecer a mesma proporcionalidade de vagas para entrada anual na sua área de atuação; III - garantir acompanhamento diário por docente ou preceptor para os estudantes de graduação e para os residentes, de acordo com a legislação vigente para a avaliação das condições de ensino e da Residência Médica; IV - dispor de projeto institucional próprio ou da IES à qual o hospital for vinculado para o desenvolvimento de atividades regulares de pesquisa científica e avaliação de tecnologias; V - dispor de mecanismos de gerenciamento das atividades de ensino e de pesquisa desenvolvidas 
A certificação deve ser renovada periodicamente. Atualmente somente são considerados hospitais de ensino aqueles certificados segundo os critérios do MS e do MEC (Brasil. Ministério da Saúde e Ministério da Educação. Portaria Interministerial no 1006/MEC/MS, de 27/05/2004; Brasil. Ministério da Saúde. Portaria no 1702/GM de 17/08/2004; Brasil. Ministério da Saúde e Ministério da Educação. Brasil. Portaria Interministerial no 2400/MEC/MS, de 02/10/2007).

A contratualização é solicitada pelo gestor municipal ou estadual junto ao MS e estabelecida entre a Secretaria de Saúde municipal e/ou estadual e o hospital de ensino, que pode ser vinculado a uma universidade federal ou estadual ou ainda, ser um hospital filantrópico, no campo de atuação de alguma universidade pública ou privada. É formalizada através de convênio/contrato onde são estabelecidas, de forma negociada e pactuada, os compromissos e obrigações das partes em contrato, as atividades a serem desenvolvidas pelo hospital, expressas em um Plano Operativo Anual (POA), os mecanismos, critérios e instâncias de monitoramento e avaliação, os recursos envolvidos e critérios de repasse, incluindo ainda outras exigências.

Os convênios/contratos têm duração máxima de cinco anos, com renovação anual do POA e orçamento, os quais podem ser revistos a qualquer momento através de Termo Aditivo, desde que acordado entre as partes.

no âmbito do hospital; VI — dispor de instalações adequadas ao ensino, com salas de aula e recursos audiovisuais, de acordo com a legislação vigente para a avaliação das condições de ensino e da Residência Médica; VII dispor ou ter acesso à biblioteca atualizada e especializada na área da saúde, com instalações adequadas para estudo individual e em grupo, e para consulta a Bibliotecas Virtuais, de acordo com os critérios vigentes para a avaliação das condições de ensino e da Residência Médica; VIII — ter constituídas, em permanente funcionamento, as comissões assessoras obrigatórias pertinentes a instituições hospitalares: a) Comissão de Documentação Médica e Estatística; b) Comissão de Ética; c) Comissão de Ética em Pesquisa, própria ou da IES à qual o hospital for vinculado; d) Comissão de Mortalidade Materna e de Mortalidade Neonatal (para hospitais que possuam maternidade); e) Comissão de Controle de Infecção Hospitalar; f) Comissão Interna de Prevenção de Acidentes; g) Comissão de Óbitos; h) Comissão de Revisão de Prontuários; i) Comissão de Transplantes e Captação de Órgãos (para hospitais que possuam Unidades de Tratamento Intensivo); j) Comitê Transfusional; k)Equipe Multiprofissional de Terapia Nutricional; IX — desenvolver atividades de vigilância epidemiológica, hemovigilância, farmacovigilância, tecnovigilância em saúde, vigilância em saúde do trabalhador e padronização de medicamentos; $\mathbf{X}$ - dispor de programa de capacitação profissional por iniciativa própria ou por meio de convênio com instituição de ensino superior; XI — participar das políticas prioritárias do Sistema Único de Saúde e colaborar ativamente na constituição de uma rede de cuidados progressivos à saúde, estabelecendo relações de cooperação técnica no campo da atenção e da docência com a rede básica, de acordo com as realidades locorregionais; XII - dedicar um mínimo de 60\% da totalidade dos leitos ativos e do total dos procedimentos praticados ao Sistema Único de Saúde: a) os hospitais públicos devem assumir o compromisso de ampliar gradualmente essa porcentagem, até atingir 100\%, num prazo de dois anos, sendo asseguradas as condições de equilíbrio econômico-financeiro no convênio com o gestor local do SUS; b) todos os benefícios decorrentes das novas modalidades conveniadas/contratuais entre os hospitais de ensino e o SUS serão proporcionais ao número de leitos e procedimentos destinados ao SUS; XIII — regular e manter sob a regulação do gestor local do SUS os serviços conveniados ou contratados, de acordo com as normas operacionais vigentes no SUS; XIV - estar formalmente inserido no Sistema de Urgência e Emergência locorregional, com definição de seu papel no Plano Estadual de Assistência a Urgência, conforme previsto na Portaria MS nº 2.048/GM, de 5 de novembro de 2002; XV - ter ações compatíveis com a Política Nacional de Humanização do Sistema Único de Saúde; XVI - garantir mecanismos de participação e controle social no hospital, possibilitando representação docente, discente, de funcionários e de usuários; e XVII - comprovar sua inclusão em programa de qualificação da gestão que cumpra o disposto pelo Ministério da Saúde e as demais esferas do SUS. 
O POA discrimina todos os serviços ofertados, a estrutura tecnológica e a capacidade instalada do hospital. Nele, constam as metas e indicadores de produção (internações, consultas ambulatoriais, atendimentos de urgência e emergência e dos serviços de apoio ao diagnóstico e tratamento); de inserção na rede; de qualificação da assistência; de aperfeiçoamento da gestão; de atuação no ensino, na formação e na educação permanente dos profissionais do hospital e da rede; e de desenvolvimento de pesquisa e de avaliação tecnológica em saúde (BRASIL. MINISTÉRIO DA SAÚDE e MINISTÉRIO da EDUCAÇÃO, 2004; BRASIL. MINISTÉRIO DA SAÚDE, 2004).

O POA e o convênio/contrato devem ser monitorados e avaliados, ao menos uma vez ao mês, por uma Comissão de Acompanhamento de Convênios/ Contratos, constituída e coordenada pela Secretaria de Saúde, com representação do hospital, da comunidade acadêmica e dos usuários (BRASIL. MINISTÉRIO DA SAÚDE e MINISTÉRIO da EDUCAÇÃO, 2004; BRASIL. MINISTÉRIO DA SAÚDE, 2004).

Importante inovação introduzida pelo Programa são os incentivos para que os hospitais desejem nele ingressar. Primeiramente, ao ingressar o hospital recebe um recurso extraorçamentário denominado de incentivo à contratualização (IAC). Além disso, o hospital passa a ter uma "orçamentação mista do custeio", composto por um valor global, fixo, negociado entre secretaria e hospital, conhecido antecipadamente, relativo aos procedimentos de média complexidade, e por um valor variável, referente aos procedimentos de alta complexidade e estratégicos, repassado retrospectivamente segundo o número de procedimentos realizados. O valor global pré-definido é subdividido em um componente fixo e outro variável diretamente vinculado ao alcance de metas e indicadores de atenção, gestão, ensino e pesquisa. Trata-se, portanto, de um sistema que articula o orçamento global ajustado por desempenho e o pagamento prospectivo por procedimentos (no caso, os de alta complexidade).

O Programa preconiza que os componentes fixo e variável do valor global correspondam a respectivamente, 85\% e 15\%. O repasse da parte fixa deve ser realizado através de transferências mensais, de forma automática e independente de qualquer avaliação prévia e o da parte variável condicionado à avaliação da Comissão de Acompanhamento, baseada em trinta indicadores, cada um com parâmetro estabelecido e pontuação definida, totalizando 32 pontos. Os indicadores referemse principalmente às ações no campo assistencial e de ensino. É desejado que o componente variável repassado segundo o desempenho alcance gradativamente até 50\% dos recursos do valor global. (BRASIL. MINISTÉRIO DA SAÚDE, 2004; BRASIL. MINISTÉRIO DA SAÚDE, 2004).

A fim de subsidiar secretarias e hospitais, o MS elaborou uma minuta de convênio/contrato e de POA que serve de referência para o estabelecimento da contratualização e para a elaboração do POA. 
Há diferentes situações no país. Existem Secretarias que condicionam o repasse do componente fixo ao cumprimento de metas físicas de produção, há outras que repassam o componente variável sem efetivamente condicioná-lo ao desempenho. Há convênios/contratos nos quais o componente variável corresponde a 10\% enquanto que em outros, a 25\% do valor global do contrato. Há também situações diversas em relação às metas que constam nos POA. Há hospitais com metas no campo da inserção na rede, da assistência, da gestão, de ensino e de pesquisa e há outros em que não há metas para o ensino e pesquisa. Há, ainda, hospitais que estabelecem contratos internos com os serviços/equipes, a partir de um plano de atividades com metas e indicadores vinculados ao POA do hospital, os quais uma vez alcançados, as equipes recebem incentivos financeiros (LIMA, 2009).

Segundo dados da SAS/MS atualizados em 14/09/2010 havia 167 hospitais de ensino certificados e 134 hospitais de ensino contratualizados.

\section{O Programa de reestruturação dos hospitais de filantrópicos no SUS}

Igualmente para os hospitais filantrópicos, no final de 2005, o MS cria o Programa de Reestruturação dos Hospitais Filantrópicos no SUS com diretrizes e metas semelhantes as dos HE, exceto as referentes ao ensino de graduação, pesquisa e avaliação tecnológica em saúde.

Embora com regras bastante semelhantes as do HE, a contratualização dos HF tem algumas especificidades a seguir discriminadas.

Como nos hospitais de ensino, a contratualização é estabelecida entre a Secretaria de Saúde estadual ou municipal, gestora plena da rede de atenção e o hospital. A Secretaria de saúde decide se contratualiza ou não o hospital, mas o Programa preconiza que sejam priorizados os hospitais onde o gestor municipal e/ou estadual já aloque recursos próprios.

Antecede a contratualização, uma etapa de adesão na qual o hospital filantrópico e o gestor municipal e/ou estadual, com homologação da Comissão IntergestoresBipartite/CIB, manifestam o desejo de ingressar no Programa. Nesta etapa o hospital já recebe 40\% do IAC. O hospital e Secretaria têm 120 dias após a adesão para concluir o convênio/contrato sob pena de suspensão de parte do incentivo do IAC (BRASIL. MINISTÉRIO DA SAÚDE, 2005). Os 60\% restantes são repassados ao hospital quando o convênio/contrato efetivamente é estabelecido entre hospital e secretaria e aprovado pela Comissão Intergestores Bipartite/CIB). Ambas as partes do IAC são repassadas em parcelas mensais para o hospital. Estes recursos devem ser ressarcidos ao MS no caso em que for constatado que as informações ou documentações fornecidas pelo hospital sejam inválidas (BRASIL. MINISTÉRIO DA SAÚDE, 2005). 
Os hospitais passam a ter um orçamento misto, composto por um valor global, fixo, negociado entre secretaria e hospital, conhecido antecipadamente, relativo aos procedimentos de média complexidade, e por um valor variável, referente aos procedimentos de alta complexidade e estratégicos, repassado através do método de pagamento prospectivo, segundo o número de procedimentos realizados.

O valor pré-definido é subdividido em um componente fixo e outro, variável. Aqui reside uma diferença em relação ao repasse de recursos dos HE. Ambos os componentes são repassados segundo o desempenho do HF, que é objeto de avaliação mensal da Comissão de Avaliação e Acompanhamento de Contratos/convênios, constituída pela Secretaria, com representantes do hospital e secretaria. O componente fixo é repassado conforme o cumprimento de metas físicas de produção, e o componente variável segundo o cumprimento de metas de qualidade de atenção e gestão. O hospital que não atingir ao menos 70\% das metas físicas pactuadas por 3 (três) ou cinco (5) meses alternados, volta a receber por meio de faturamento dos procedimentos para o SUS por um período de dois (2) meses, quando então deve ser pactuado entre secretaria e hospital um novo POA. O hospital será desligado do Programa se não for pactuado um novo POA ou ainda se não cumprir 70\% das metas físicas pactuadas no novo POA por três (3) meses consecutivos, voltando a receber por procedimento (BRASIL. MINISTÉRIO DA SAÚDE, 2005).

O Programa preconiza que os componentes, fixo e variável, do valor global devam corresponder respectivamente a 90\% e a 10\% e é também recomendado que gradativamente o percentual do componente variável alcance 50\% (BRASIL. MINISTÉRIO DA SAÚDE, 2005). No mais as regras são semelhantes as do HE (BRASIL. MINISTÉRIO DA SAÚDE, 2005).

Segundo dados da SAS/MS atualizados em 15/10/2010 havia 633 hospitais filantrópicos contratualizados.

\section{A política nacional dos hospitais de pequeno porte - HPP}

Considerando a necessidade de buscar alternativas de inserção na rede de atenção do SUS e de financiamento para os hospitais com 5 a 30 leitos, ainda em 2004, o MS implementou uma Política para os HPP, estimulando a formação de rede microrregionais de serviços articuladas e resolutivas na qual os HPP cumpririam a função de assegurar a continuidade da atenção prestada pela atenção básica e equipes de saúde da família e a realização da média complexidade (BRASIL. MINISTÉRIO DA SAÚDE, 2004). Note-se que, como observado em Barbosa et al, 2002, até então os hospitais filantrópicos de pequeno porte superpunham grande parte de sua produção à do Programa de Saúde da Família. 
Nessa modalidade de contratualização, a Secretaria estadual ou municipal de saúde, gestora plena da rede, encaminha ao MS, após apreciação e aprovação pelo Conselho de Saúde e pela Comissão Intergestores Bipartite (CIB), o Termo de Adesão à Política Nacional dos HPP com um plano de trabalho que discrimina metas e ações a serem implementadas pelos hospitais. A alocação dos recursos de custeio nos HPP passa a ser realizada através de um orçamento global cujo repasse é condicionado à execução do plano de trabalho, sendo ambos discriminados em um Contrato de Metas (BRASIL. MINISTÉRIO DA SAÚDE, 2004).

O acompanhamento e a avaliação do desempenho dos HPP são realizados por um Conselho Gestor ou por uma Comissão de Acompanhamento constituídos no âmbito do Conselho de Saúde que analisa o cumprimento das metas e indicadores do plano de trabalho contidos no Contrato de Metas para repassar os recursos financeiros para o hospital. O não cumprimento das diretrizes da Política Nacional dos HPP e das obrigações contidas no Contrato de Metas implicará na suspensão dos recursos pactuados (BRASIL. MINISTÉRIO DA SAÚDE, 2004).

Segundo dados da SAS/MS, de 14/09/2010 havia 2.568 hospitais de pequeno porte que aderiram à Política e, destes, apenas 506 contratualizados.

\subsubsection{Os contratos de gestão entre a Secretaria Estadual de Saúde de São Paulo e as organizações sociais de saúde}

O Governo do Estado de São Paulo através de Lei complementar n 846, de 04/06/1998 habilitou entidades públicas de direito privado, não estatais, com finalidade social, sem fins lucrativos e com autonomia administrativa e financeira, as Organizações Sociais de Saúde/OSS para gerenciar equipamentos de saúde da Secretaria Estadual de Saúde, com a obrigatoriedade de atenderem exclusivamente ao SUS.

Inicialmente habilitadas para gerenciar 15 hospitais, atualmente as OSS gerenciam 34 hospitais, 38 ambulatórios, 1 centro de referência, 2 farmácias e 3 laboratórios de análises clínicas (SECRETARIA DE ESTADO DA SAÚDE DE SÃO PAULO, 2010).

As OSS são reguladas pela SES através de contratos de gestão renovados a cada ano, nos quais há um plano de atividades, um valor de recursos para executálo, critérios de repasses destes recursos, mecanismos e instâncias de avaliação, dentre outras condições.

Os contratos de gestão são monitorados e avaliados trimestralmente por uma comissão de acompanhamento especificamente constituída pela SES para tal finalidade. Na avaliação são definidos os percentuais de repasse, as necessidades de aditivos contratuais ou de redução de metas, podendo inclusive, se necessário indicar a desqualificação da OSS. Além disso, as OSS estão sujeitas a auditorias da SES e do Conselho Estadual de Saúde e ao controle do Tribunal de Contas (SANO e ABRUCIO, 2008). 
O valor total dos recursos do contrato de gestão pactuados para realização das atividades é repassado da seguinte forma: 90\% em 12 parcelas mensais vinculadas ao cumprimento de ao menos $85 \%$ das metas físicas de produção (percentuais menores implicam em redução nos pagamentos subsequentes) e 10\% em quatro parcelas trimestrais condicionada ao alcance de indicadores de qualidade. Há também duas avaliações semestrais que de acordo com as metas atingidas podem alterar o valor total previsto em contrato (SANO e ABRUCIO, 2008).

Os contratos de gestão ao longo de 12 anos de experiência foram sendo aperfeiçoados. Nos primeiros contratos, o grau de exigência e de abrangência das metas era menor. As metas físicas de produção não eram especificadas por serviços e especialidades e sim consideradas em grandes blocos — ambulatório, pronto socorro e internação e as metas de qualidade se restringiam a taxa de infecção, taxa de cesárea, taxa de letalidade e indicador de satisfação da clientela. Atualmente, as metas são mais abrangentes e mais exigentes no campo da qualificação da gestão e da qualificação, do acesso da população, além das metas físicas de produção.

\subsubsection{Os termos de compromisso dos hospitais do programa hospitalar - PROHOSP - e das equipes de saúde da família na atenção básica, da Secretaria Estadual de Saúde de Minas Gerais - SES/MG}

A SES /MG através de Resolução interna instituiu em 2003 o Programa de Fortalecimento e Melhoria da Qualidade dos Hospitais/PROHOSP, introduzindo importante e talvez pioneira mudança na lógica de relação, que passou de convenial para a contratual, entre Estado e hospitais públicos e privados sem fins lucrativos prestadores de serviços ao SUS (MINAS GERAIS, 2003).

O PROHOSP consolidou a regionalização de saúde materializando através do contrato, o planejamento regional saúde. São critérios para ingresso no Programa ser hospital público ou filantrópico com mais de 100 leitos desempenhando as funções de hospitais-polo macro ou microrregionais e atender ao SUS (MINAS GERAIS, 2003).

Os hospitais selecionados têm aporte diferenciado e adicional de recursos do tesouro do Estado, especificamente do PROHOSP, mediante a assinatura de Termo de Compromisso com a SES, com a interveniência da Secretaria Municipal de Saúde/ SMS do município, sede da macrorregião de saúde. No referido Termo são definidos indicadores e metas no campo da atenção e da gestão, além de estabelecida a aplicação dos recursos: 40\% destinam-se à melhoria da qualidade da atenção, à manutenção e ampliação da capacidade instalada (física e equipamento); 10\% à melhoria da gestão hospitalar; e 50\% são livres de vinculação (MINAS GERAIS, 2003).

Os gestores municipais e a direção do hospital elaboram de forma pactuada um Plano de Ajustes e Metas estabelecendo metas assistenciais, qualitativas e quantitativas, além de metas gerenciais, indicadores para mensuração dos resultados, 
recursos financeiros necessários à sua execução, obedecendo aos percentuais de destinação de recursos já mencionados. São exemplos de metas: a adesão à política de humanização da assistência hospitalar, o desenvolvimento e implantação de protocolos clínicos, a realização de procedimentos de média e alta complexidade insuficientes na Região de Saúde, a implantação de uma gestão profissional, de sistema de custos, de controle interno e de controle de estoques, a adesão ao banco de preço, a participação em processo de capacitação gerencial ofertado pela SES, a elaboração de um Plano Diretor, etc (MINAS GERAIS, 2003).

A SES designa uma Comissão de Avaliação dos Planos de Ajustes e Metas para acompanhamento da execução e avaliação dos indicadores e metas pactuados e os recursos são repassados segundo o seu alcance (MINAS GERAIS, 2003).

Igualmente para a atenção básica, a SES/MG cria o Projeto Estruturador da Saúde em Casa, visando a qualificar a Atenção Primária à Saúde/APS desenvolvida nos municípios através das Equipes de Saúde da Família/PSF e das Unidades Básicas de Saúde/ UBS. Há uma pactuação, formalizada através de Termo de Compromisso/ TC, entre a SES e os municípios que aderirem ao projeto, estabelecendo metas e indicadores de desempenho, responsabilidades, condições para execução, concessão de incentivos, e critérios de fiscalização e de monitoramento e avaliação do desempenho do município. O desempenho dos municípios é avaliado pelas Gerências Regionais de Saúde da SES e por uma Comissão de Acompanhamento e Avaliação instituída pelo CIB microrregional. O TC tem validade máxima de cinco anos, mas anualmente podem ser revistas as metas e indicadores mediante Termo Aditivo (MINAS GERAIS, 2009).

Há um sistema de incentivos previsto para os municípios e para as equipes de APS. No Termo de Compromisso fica estabelecido que a Secretaria Municipal de Saúde receba um bônus de desempenho (recursos financeiros adicionais) se: cumprir as metas e indicadores da APS; estabelecer Contrato de Gestão por Resultados com as equipes de atenção primária tendo em vista as metas e indicadores do TC pactuados com a SES; estabelecer uma comissão de acompanhamento e avaliação para monitorar o desempenho do TC do município (MINAS GERAIS, 2009).

Este bônus pode ser repassado para as equipes de atenção primária à saúde na forma de um incentivo financeiro mensal condicionado ao alcance de metas e indicadores do Contrato de Gestão por Resultados estabelecido entre as equipes de APS e a SMS (MINAS GERAIS, 2009).

\subsubsection{Os contratos de gestão ou termos de compromissos na atenção básica da Secretaria Municipal de Saúde de Curitiba}

A SMS de Curitiba estabelece contratos internos, denominados Termo de Compromisso/TERCOM, desde 2003, entre o nível central da Secretaria, os Distritos 
Sanitários e as Unidades Básicas de Saúde, renováveis a cada ano, tendo como referência o Plano Municipal de Saúde e a Programação Anual de Saúde, além de outros documentos de planejamento (MARTY, 2010).

Acoplado aos mecanismos de monitoramento e avaliação estabelecidos, há um sistema de incentivos aos trabalhadores, denominado de Incentivo de Desenvolvimento de Qualidade (IDQ), que se constitui em remuneração adicional e vinculada ao desempenho profissional com vistas à melhoria da atenção prestada aos usuários (MARTY, 2010). O IDQ pode representar de 20 a 40\% do salário do profissional.

O TERCOM tem um Plano Operativo Anual /POA onde constam metas e indicadores a serem alcançados pelas Unidades Básicas de Saúde. As metas são pactuadas considerando as possibilidades locais de infraestrutura, recursos humanos assim como a série histórica de produção. O monitoramento do POA é realizado a cada três meses. O pagamento do IDC é realizado mensalmente considerando, além da avaliação do POA, a avaliação da comunidade, da Chefia da UBS e de uma autoavaliação (MARTY, 2010).

\subsection{Apreciação Geral dos Novos Sistemas de Alocação de Recursos Adotados em Modelos de Contratualização no Brasil}

Todas as experiências brasileiras apresentadas de alocação de recursos com base no desempenho têm em comum a utilização de algum tipo de arranjo contratual, denominado de diferentes formas em cada uma delas, mas que em síntese se expressa em um instrumento formal assinado entre duas partes, o contratante e o contratado, que, em negociação, estabelecem compromissos e responsabilidades em relação à prestação de serviços de saúde. Pode-se observar que o tripé de sustentação do arranjo contratual é constituído por três elementos: (1) um plano de atividades com recursos financeiros definidos para sua execução; (2) um sistema de monitoramento e avaliação das metas e indicadores relacionados às atividades contidas no referido plano; e (3) um sistema de incentivos que vincula o repasse de recursos financeiros ao alcance das referidas metas e indicadores.

Nas experiências em curso no país, de forma mais ou menos consolidada e estruturada, na dependência do desenvolvimento organizacional dos contratantes e contratados, as partes em contrato, de forma pactuada, constroem o referido tripé.

O contratante, nos casos apresentados, é sempre um ente estatal pertencente à administração pública direta estadual ou municipal (Secretaria de Saúde estadual ou municipal) e o contratado (prestador hospitalar ou de atenção básica) pode ser um ente estatal, da mesma esfera de governo ou não, ou ainda um ente privado sem fins lucrativos. 
Os incentivos financeiros, nestas experiências, podem ser exclusivamente vinculados ao desempenho da unidade hospitalar ou de atenção básica ou podem adicionalmente serem condicionados ao desempenho da equipe profissional. É importante ressaltar que todas as experiências mantêm outras modalidades de alocação de recursos (em geral, o orçamento global) aos prestadores que representam a maior parte dos recursos de manutenção /custeio dos mesmos.

Não há, ainda, uma avaliação do impacto das experiências apresentadas sobre a efetiva melhoria do desempenho dos hospitais e da atenção básica, no que se refere à política de contratualização do MS, no âmbito nacional. Entretanto, em estudo realizado em quatro secretarias contratantes e hospitais de ensino contratados observou-se que, na percepção dos entrevistados, houve um aumento de produção de procedimentos de média complexidade e, em alguns casos, dos de alta complexidade, assim como uma maior inserção desses hospitais na rede de serviços, porém não foi observada melhoria na qualidade da atenção (LIMA, 2009).

Quanto à experiência das OSS da SES com os hospitais, há estudos que evidenciam resultados positivos no que se refere à eficácia e eficiência dos gastos e à gestão de recursos humanos especialmente quando comparados com os hospitais estatais paulistas (SANO \& ABRUCIO, 2008).

\section{5 | CONSIDERAÇÕES FINAIS}

A integralidade do cuidado à saúde é, sem dúvida, um dos principais desafios do SUS aos seus vinte anos de existência. Para a consecução desse objetivo, é imprescindível a estruturação e condução de uma rede integrada de serviços, o que implica em repensar o modelo de municipalização à outrance levado a cabo no SUS até hoje e requer o fortalecimento da esfera estadual, a quem compete o desenho e a estruturação de regiões sanitárias com redes intermunicipais integradas de serviços.

Por sua vez, a capacidade de condução do sistema estadual de saúde, regionalizado, a partir de redes integradas de serviços requer, de um lado, fortalecer a capacidade técnica e política ${ }^{13}$ dos gestores do SUS e, por outro, adotar instrumentos de condução e regulação dos prestadores de serviços de saúde, dentre os quais figuram:

- modelos de contratualização entre o gestor público e prestadores de serviços de saúde;

13 Referimo-nos ao fortalecimento de: (i) a capacidade técnica dos gestores estaduais para conceber e estruturar uma rede integrada de prestadores de serviços de saúde (que compreenda todos os níveis e tipos de atenção) e, portanto, identificar o papel e as metas que cada prestador deve cumprir nessa rede e (ii) a capacidade política do gestor estadual e dos gestores municipais para negociar e pactuar a constituição de uma rede de serviços que possibilite a integralidade do cuidado em saúde e que supere as fronteiras municipais. 
- um sistema de alocação de recursos aos prestadores de serviços que supere o mero pagamento por serviços previamente prestados (através dos sistemas SIH e SIA-SUS) ou o orçamento global sem nenhum ajuste ou condicionalidade a melhoria nos processos de atenção e resultados sobre a saúde da população.

É nesse contexto que se insere a temática dos sistemas de alocação de recursos aos prestadores de serviços de saúde.

Em linhas gerais, pode-se afirmar que:

- é necessário pensar em sistemas de alocação de recursos que induzam e/ou fortaleçam a construção e implantação de linhas de cuidado integral;

- nesse sentido, sugerem-se sistemas diferenciados, por nível de atenção: (i) aos prestadores da atenção primária, que deveriam se responsabilizar por essas linhas de cuidado integral, corresponderia uma alocação de recursos per capita ajustada pelo risco da população a eles adscrita; (ii) os hospitais, por sua vez, receberiam recursos através de orçamento global correspondente ao volume da produção programada para o período, levando em conta o seu perfil (case-mix);

- tanto no caso da atenção primária como no da atenção hospitalar, a alocação de recursos correspondente deve ser condicionada ou ajustada a uma avaliação de desempenho que contemple tanto aspectos relacionados processos (eficiência e qualidade) como, principalmente, os resultados sobre a saúde da população (a efetividade das ações dos serviços de saúde);

- o desempenho deve ser mensurado através de indicadores que, portanto, pertençam a várias dimensões (qualidade/ adequação do cuidado, eficiência da produção de serviços, efetividade das ações dos prestadores) e cujo benchmark se altere com o passar do tempo. Os próprios indicadores devem ser revistos e, portanto, podem variar ao longo dos anos, em função de prioridades estabelecidas pelos gestores do sistema regional ou microrregional;

- o processo de estabelecimento desses indicadores de desempenho e de seus padrões deve envolver os prestadores, 
tendo em vista a definição de padrões factíveis como o compromisso dos prestadores com o alcance das metas da política sanitária e seus respectivos indicadores.

Deve-se destacar que esta proposta geral só é implementável no contexto de um sistema regionalizado que, por um lado, se responsabilize pela população adscrita em seu território e, por outro, integre os diversos prestadores de serviços de saúde (de distintos níveis da atenção). Neste modelo, os núcleos de atenção primária têm um papel central no sistema de saúde, responsabilizando-se pela atenção integral da população adscrita através de linhas de cuidado definidas a partir do perfil epidemiológico dessa população.

Por outro lado, não se pode atribuir ao sistema de alocação de recursos aos prestadores o poder de mudar drasticamente os resultados na saúde da população. São necessárias, também, ações intersetoriais que envolvam os poderes públicos que atuam sobre os determinantes sociais da saúde (educação, renda, saneamento, dentre outros). 


\section{6 | REFERÊNCIAS BIBLIOGRÁFICAS}

AFONSO, P.B. Contratualização em ambiente de cuidados de saúde primários. Revista Portuguesa de Saúde Pública, n.9, 2010.

BARBOSA P.R et al. Hospitais Filantrópicos no Brasil. Rio de Janeiro: BNDES, vol 1, 2002.

BMJ. BMJ ClinicalEvidenceHandbook. London: BMJ Publishing, 2007.

BRASIL. MINISTÉRIO DA SAÚDE E MINISTÉRIO DA EDUCAÇÃO. Portaria Interministerial no 1006/MEC/MS, de 27/05/2004.

BRASIL. MINISTÉRIO DA SAÚDE. Portaria no 1702/GM de 17/08/2004.

BRASIL. MINISTÉRIO DA SAÚDE E MINISTÉRIO DA EDUCAÇÃO. Portaria Interministerial no 2400/MEC/MS, de 02/10/2007.

BRASIL. MINISTÉRIO DA SAÚDE. Portaria GM nº 1703 de 17/08/2004.

BRASIL. MINISTÉRIO DA SAÚDE. Portaria GM n² 2532de 26/10/2004.

BRASIL. MINISTÉRIO DA SAƯDE. Portaria GM nº 1044 de 01/06/2004.

BRASIL. MINISTÉRIO DA SAƯDE. Portaria GM nº 1.721 de 21/09/2005.

BRASIL. MINISTÉRIO DA SAÚDE. Portaria SAS n。 635 de 10/11/2005.

BRASIL. MINISTÉRIO DA SAÚDE. Portaria GM nº 3.123 de 07/12/2005.

BRASIL. MINISTÉRIO DA SAÚDE. Portaria GM nº 1.044 de 01/06/2004.

CAMPBELL, S.M; et al. Effects of pay for performance on the quality of primary care in England. New England Journal of Medicine, n. 361, v.4, 2009.

CARTER, G.M; NEWHOUSE, J.P. \&RELLES, A. How much change in the Case Mix Index is DRG Creep? Journalof Health Economics, v. 9, 1990.

CHIYOSI, F. \& MOURA, A. O Sistema de Assistência Médico-Hospitalar da Previdência Social (SAMHPS) - Sistema AIH. Rio de Janeiro, mimeo, s/d.

CHRISTIANSON, J; LEATHERMAN, S. \& SUTHERLAND, K. Financial incentives, healthcare providers and quality improvements. A review of evidence. London: The Health Foundation, 2007.

CHULIS, G. Assessing Prospective Payment. Medical Care Review, n. 48, v.2, Summer, 1991.

CYLUS, J. \& IRWIN, R. The challenges of hospital payment systems. Euro Observer, v. 12, n.3, Autumn 2010.

DOCTEUR, E. More value for money: improving efficiency in OECD health systems. Berlin: OECD, 2004.

Escoval, A; Coelho, A; Diniz, J; Rodrigues, M; Moreira, F. \& Espiga, P. Gestão integrada da doença: uma abordagem experimental de gestão em Saúde. Revista Portuguesa de Saúde Pública, n.9, 2010 
FEINGLASS, J. \& HOLLOWAY, M.D. The initial impact of the Medicare Prospective Payment System on U.S. health care: a review of literature. Medical Care Review, n. 48, v.1, Spring, 1991.

GAY, E.G; KRONENFELD, J; BAKER, S \&AMIDON, R. An appraisal of organizational response to fiscally constraining regulation: the case of hospitals and DRGs. Journal of Health and Social Behaviour, v. 30, 1989.

GIUFFRIDA, A et al. Target payments in primary care: effects on professional practice and health care outcomes (Cochrane Rewiew). Oxford: The Cochrane Library, Issue 3.: 2000.

GOVERNO DE MINAS GERAIS. Resolução SES no 0082, de 16/05/2003.

GROSSBART, S. What's the Return? Assessing the Effect of "Pay-for-Performance" Initiatives on the Quality of Care Delivery. Medical Care Research and Review, v. 63, n. 1, 2006.

GUTERMAN, S. \& DOBSON, A. Impact of the Medicare Prospective Payment System for Hospitals. Health Care Financing Review, n. 7, v.6, Spring, 1986.

HORNBROOK, M.C. \& BERKI, S. Practice Mode and Payment Method: effects on use, costs, quality and access. Medical Care, n.23, v.5, May 1985.

INSTITUTE OF MEDICINE/IOM. Committee on Quality of Health Care in America. Aligning Payment Policies with Quality Improvement in Crossing the Quality Chasm: A New Health System for the 21st Century. National Academy Press, Washington, D.C., 2001. Cap 8 p 181-206.

KAZANDJIAN, V. Pay-for-performance in health care: the natural evolution of performance measurement and community expectations. Revista Portuguesa de Saúde Pública, n.9, 2010.

LIMA SML. Possibilidades e limites da contratualização no aprimoramento da gestão e da assistência em hospitais: o caso dos Hospitais de Ensino no Sistema Único de Saúde brasileiro. Tese apresentada com vistas à obtenção do título de Doutor em Ciências na área de Saúde Pública. Escola Nacional de Saúde Pública/Fundação Oswaldo Cruz, 2009.

MARTY, IK. Primeiras experiências de contratos de gestão em Curitiba: Secretaria Municipal de Saúde. In Gestão para resultados em Curitiba - A experiência de contratualização, cap IV, 2010.

MAYNARD, A. Payment for Performance (P4P): International experience and a cautionary proposal for Estonia. Health Financing Policy Paper, Division of Country Health Systems, World Health Organization, 200.8

ORTÚN, V. (org.) El Buen Gobierno Sanitario. Economía y Gestión Sanitaria. Madrid: Springer Healthcare Communications, 2009.

ORTÚN, V. De la evaluación a la Gestión: acortar la brecha entre eficacia y efectividad. Ekonomiaz, N. 60, V. 1, Tercer Cuatrimestre, 2005.

PEIRÓ, S. Comentario. Gestión Clínica y Sanitaria, v. 11, n.2, Verano de 2009.

SANO,Hironobu; ABRUCIO, F. L. Promessas e Resultados da Nova Gestão Pública no Brasil: o caso das Organizações Sociais de Saúde em São Paulo. RAE. Revista de Administração de Empresas, v. 48, p. 64-80, 2008. Disponível em http://www.scielo.br/scielo.php?script=sci_arttext\&pid=S003475902008000300007\&lng=pt\&nrm=iso\&tlng=pt. Acessadoem 22/06/2010 
SCHREYOGG, J. STARGARDT, T; TIEMANN, O. \& BUSSE, R. Methods to determine reimbursement rates for diagnosis related groups (DRG): A comparison on nine European countries. Health Caare Management Science, n. 9, 2006.

TANENBAUM, S. Pay for Performance in Medicare: Evidentiary Irony and the Politics of Value. Journal of Health Politics, Policy and Law v. 34, n. 5, 2009.

UGÁ, M.A.D. Sistemas de repasses financeiros a unidades de assistência à saúde: uma proposta preliminar para a rede pública brasileira. In: O financiamento da saúde no Brasil. Série Economia e Financiamento No. 4. Organização Pan-Americana da Saúde, Representação do Brasil. Brasília: 1994.

UGÁ, M.A.D. As propostas de reforma dos sistemas de saúde no contexto do ajuste macroeconômico. Tese de Doutorado, Instituto de Medicina Social da UERJ. Rio de Janeiro, 1997.

UGÁ, M.A.D. O Sistema de Pagamento Prospectivo por Procedimento: a Experiência NorteAmericana. Cadernos FUNDAP, v. 38, n. 19. São Paulo: FUNDAP, 1996.

UGÁ, M.A.D. Sistemas de repasses financeiros a hospitais: o método de pagamento prospectivo e sua implementação através do sistemas SIA e SIH/SUS. Dissertação de Mestrado, Instituto de Economia da UFRJ, Rio de Janeiro, 1992.

WENNBERG, J.E. \& GITTELSOHN, A. Variations in medical care among small areas. Science, 246, V.4, 1973. 